\title{
Bonwill's Triangle in Greek Human Mandibles
}

\author{
Fotoula Nikolopoulou ${ }^{1 *}$, Anestis Xrysostomidis ${ }^{2}$, Xristina Psari², Maria Piagkou ${ }^{3}$ and Theodoros Troupis ${ }^{4}$
}

${ }^{1}$ Assistant Professor Dental School National and Kapodistrian University of Athens, Greece

${ }^{2}$ Medical School, National and Kapodistrian University of Athens, Greece

${ }^{3}$ Assistant Professor, Medical School National and Kapodistrian University of Athens, Greece

${ }^{4}$ Associate Professor of Anatomy, Chair of the Department of Anatomy, Medical School, National and Kapodistrian University of Athens, Greece

Submission: September 27, 2019; Published: October 23, 2019

*Corresponding author: Fotoula Nikolopoulou, Assistant Professor of the Dental School of National and Kapodistrian University of Athens, Greece

Summary

This investigation was carried out at the Department of Anatomy of the Medical School National and Kapodistrian University of Athens. Nineteen [19] Greek human mandibles were examined [10 male and 9 females]. For all the skeletons, sex, age and cause of death were recorded.

The examination of Bonwill's triangle was obtained by examining the following dimensions:

i. Distance between the middle condylar point and middle insical point.

ii. Distance between the left and the right middle condylar points.

The results were in accordance with Bonwill's triangle. It was observed that Bonwill's triangle in Greek human mandibles were equilateral about $101 \mathrm{~mm}$.

There was no difference in the dimension of triangle between male and female.

Keywords: Bonwill's Triangle; Intercondylar Distance; Human Mandibles

\section{Introduction}

In 1858 an American dentist, G Bonwill described an equilateral triangle, which was the basis for Bonwill's theory of occlusion. The equilateral triangle had $100 \mathrm{~mm}$ [4inches] formed by lines joining the medial contact point of the incisors and the centers of the mandibular condyles [1,2]. Bonwill based this theory on measurements of 6.000 skulls and 4.000 living persons [3]. A literature review shows that the ideal arch is considered to be symmetrical. Hawley based on the earlier work of Bonwill, described the ideal arch as being constructed upon an equilateral triangle with slight modifications [4]. Some later investigators Lenhossek, Izard, Jovanovic showed that the sides of this triangle may vary somewhat in length relative to another. These authors pointed out that Bonwill's triangle was usually more or less equilateral, although its sides were frequently of a length less than $10 \mathrm{~mm}$, especially in the female [5]. They also showed that the sides of Bonwill's triangle in 224 Yugoslav mandibles were rarely of equal length [6].

Baz determined normal arch size by a 'geometric construction' based on measurements taken directly on the patient's face. This was a development of Hawley's method of arch predetermination [7]. Wilson examined 300jaws and found 6\% in accordance with
Bonwill's theory [8]. It has been referred that variations in the size of Bonwill's triangle influence the angulations of cusp for complete dentures [8]. The construction of average articulators is generally in accordance with Bonwill's theory and Monson's pyramid is also based on Bonwill's triangle [9]. Monson associated Bonwill's triangle with his observations and formulated his spherical theory. The condylar path and occlusal plane form a curve which is part of an 8 inches sphere. The center of this sphere is common center of the mandibular motion. This sphere touches the apices of the Bonwill's triangle [10]. The shape of the mandible and the size of Bonwill's triangle have significance in clinical prosthetics as well as an anthropological interest. The symmetry and asymmetry have always been an interesting subject of study by scientists of different fields, for example anatomists, anthropologists, dentists, orthopedists and others. The aim of our investigation was to estimate Bonwill's triangle in Greek human mandibles.

\section{Materials and Methods}

This study was carried out at the Department of Anatomy of the Medical School National and Kapodistrian University of Athens. Nineteen mandibles [10 males and 9 females] were examined. For all the skeletons, sex, age and cause of death were recorded. It has 


\section{Advances in Dentistry \& Oral Health}

been used on the assumption that the studied mandibles were not mixed and retain consistent hereditary characteristics. The study of Bonwill's triangle was formed by lines joining the medial contact point of the mandibular central incisors and the centers of the mandibular condyles. Bonwill's triangle was obtained by following the dimensions:

a) The distance between the middle condylar point and the middle incisal point

b) The distance between the left and middle condylar points. All the measurements were taken with sliding caliper. The mandibles were placed in horizontal position (Figure 1).

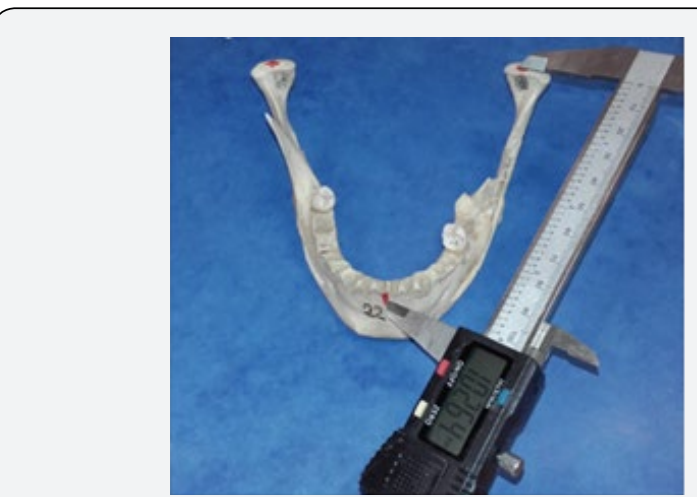

Figure 1: The distance between the left and middle condylar points. All the measurements were taken with sliding caliper. The mandibles were placed in horizontal position.

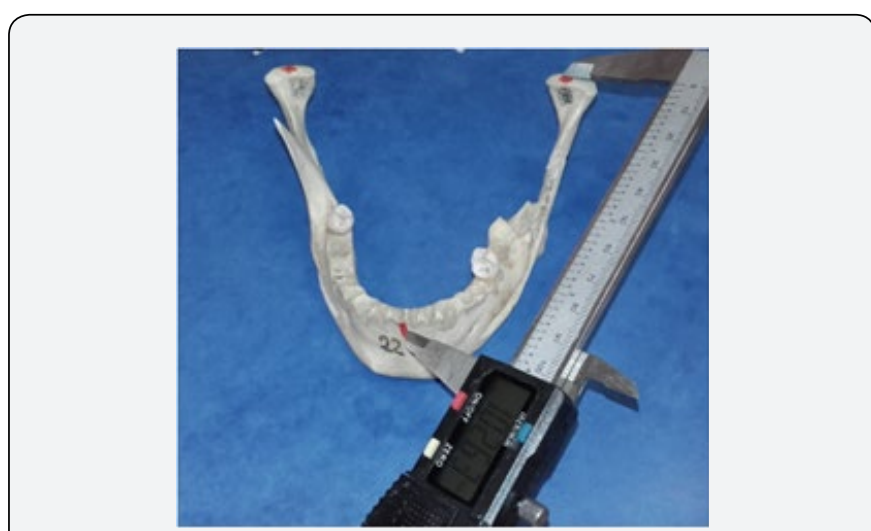

Figure 2: The distance between the left and middle condylar points. All the measurements were taken with sliding caliper. The mandibles were placed in horizontal position.

From the anthrometrical point of view empirical methods were not the most satisfactory, but in this case, there was alternative (Figures 1-3).

\section{Results}

This study was performed using the sample t-test for independent samples with equal variances. It has been showed from (Tables $1 \& 2$ ) that the Bonwill's triangle was equilateral in Greek mandibles. All the examined dimensions were also smaller in female mandibles than male mandibles. The standard deviations and standard errors of the mean were larger in the female (Tables 1 \& 2). It reflects the small sample of female mandibles. Our calculated $t$ was $t=1,65$ and degrees of freedom $[n 1+n 2-2=17]$ $\mathrm{df}=17$. The calculated $\mathrm{t}$ was smaller than the critical value $\mathrm{t}=1$, 74 [11]. We concluded that our t-test was no significant. T-test demonstrated that there was no difference of the dimension of the Bonwill's triangle between male and female.

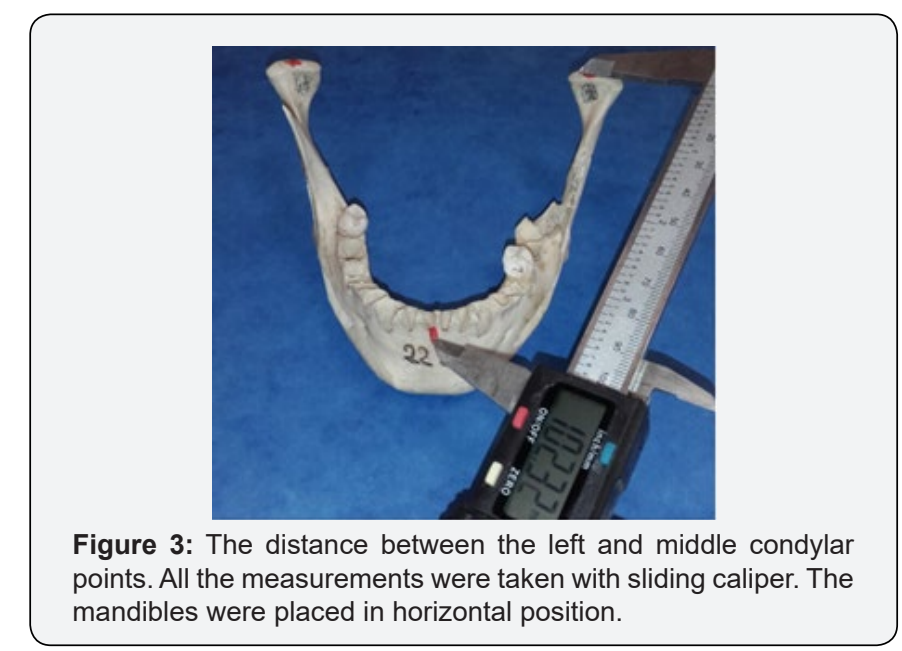

Table 1: Dimension of female Greek mandible.

\begin{tabular}{|c|c|c|c|c|}
\hline Dimension & Number & Mean & SD & SE \\
\hline Left condylar-incisal & 9 & 101,38 & 1,94 & 0,64 \\
\hline Right condylar-incisal & 9 & 101,24 & 1,37 & 0,456 \\
\hline Breadth & 9 & 101,38 & 1,94 & 0,64 \\
\hline
\end{tabular}

Table 2: Dimension of the male Greek mandible.

\begin{tabular}{|c|c|c|c|c|}
\hline Dimension & Number & Mean & SD & SE \\
\hline Left condylar-incisal & 10 & 101,72 & 1,34 & 0.42 \\
\hline Length & 10 & 102,4 & 1,21 & 0,38 \\
\hline Right condylar-incisal & 10 & 102,4 & 1,21 & 0,38 \\
\hline $\begin{array}{c}\text { length } \\
\text { Middle bicondylar } \\
\text { Breadth }\end{array}$ & & & & \\
\hline
\end{tabular}

\section{Discussion}

The objectives of this discussion will be to analyze and reappraise the Bonwill's triangle as it is applied for the construction of the complete dentures. Variations in the size of the Bonwill's triangle influence the cusp angulation for complete dentures. Monson based on Bonwill's triangle said the condylar path and occlusal plane form a curve which is a path of an 8 inches sphere. This sphere touches the apices of the Bonwill's triangle. The Balkwill angle is formed between occlusal plane and the Bonwill's triangle. Bosse measured 500 human mandibles and found a marked variation in the distance between the condyles. He found an average distance of $96 \mathrm{~mm}$ by measuring from the middle of the mesial surface of one condylar to the lateral surface of the other $[8,12]$. Choquet [13] measured 149 jaws and concluded that the internal distance between the condyles was from $65 \mathrm{~mm}$ to $96 \mathrm{~mm}$. He also mentioned the asymmetric position of the condyles [13]. Amoedo [14] referred that the distance between the condyles varied from $70 \mathrm{~mm}$ to $130 \mathrm{~mm}$ [14]. 
Wilson [15] examined 300 mandibles and concluded that 6 per cent of them were in accordance with Bonwill's theory [15]. The above investigators measured mandibles on dried skulls. It is known that dried bones change form [13]. The results of our investigation showed that the triangle was equilateral in accordance with Bonwill's theory. All the examined dimensions were smaller in female jaws than male ones. Zivanovic [5] measured the triangle in East African mandibles and concluded that overall they were greater than the dimensions of European populations. He presented an isosceles triangle because of the elongation of the mandibles [5]. Intercondylar distances had been determined by means of the condylator's face bow between the arbitrary hinge axis points on the skin for 300 men and 300 women were statistically compared. The mean intercondylar distance for men was $115,2 \mathrm{~mm}$ and for women was $105,4 \mathrm{~mm}$, for Turkish population [16]. The differences were highly significant $[p<0,001]$ [16]. Our results showed that there were no differences in Greek population between men and women. In a sample of the Croatian population the intercondylar distance was ranged from $110 \mathrm{~mm}$ to $138 \mathrm{~mm}$ with the mean of $126 \mathrm{~mm}$. The authors' conclusions were based on patients' radiographs [17]. Our measurements were taken by using sliding caliper.

Some authors used intercondylar width as a guide to set up complete denture teeth. They tried to determine if there was a relationship between intercondylar distance and inter-arch distance between upper canines, upper first molars, lower canines and lower first molars in denture subjects [18-20]. However, the correctness of Bonwill's theory has been questioned. The results of Bonwill's triangle on living persons had not had sufficient scientific proof [2,11]. As was discussed in the review of the literature, very few studies have examined the variations in size of Bonwill's triangle and the correlation on the cusp angulation. A larger study would be needed to evaluate the morphologic differences in Greek human jaws.

\section{References}

1. PG Stimson, CA (1997) Mertz Forensic Dentistry. CRC Press, London, UK p. 4-6.

2. G Zarb, C Bolender, G Carlsson (1998) Boucher's Prosthodontic Treatment for edentulous patients. $11^{\text {th }}$ edn. ST Louis, Mosby co pp. 197-199.
3. WGA Bonwill (1899) The Scientific Articulation of the Human Teeth as Founded on Geometrical, Mathematical, and Mechanical Laws. Dent Items Interest 21: 617-643.

4. SJ Rudge (1981) Dental arch analysis: arch form. A review of the literature. Eur J Orthod 3(4): 279-284.

5. S Zivanovic (1969) Bonwill's triangle and asymmetry in East African Human Mandibles. Arch Oral Biol 14(9): 1041-1044.

6. N Gudnara, S Zivanovic (1968) Asymmetry in East African Skulls. Am J Phys Anthrop 28(3): 331-337.

7. D Baz (1958) Analysis of dental arch form. Int Dent J 8: 291-294.

8. FT Christensen (1959) The effect of Bonwill's triangle on complete dentures. J Prosth Dent 9(5): 791-796.

9. HR Sonstebo (1961) Walker's improvements of Bonwill's system. J Prosth Dent 11(6): 1074-1079.

10. LA Weinberg (1963) An evaluation of basic articulators and their concepts. Part II Arbitrary semi adjustable articulators. J Prosth Dent 13(4): 645-663.

11. Murray R Spiegel, Larry J (1998) Stephens Statistics $3^{\text {rd }}$ edition, Mc Graw-Hill, New York, USA, pp. 250-258.

12. E Ohm, J Silness (1982) The size of the Balkwill angle and the height of the Bon will triangle. J Oral Rehabil 9(4): 301-306.

13. J Choquet (1909) The triangle equilateral de Bonwill. L' Odontologie 41: 307-312.

14. 0 Amoedo (1913) Simplification dans l' enregistrement de la trajectoire condylienne. Revue trimestrielle suisse d' odontology 23: 157175.

15. GH Wilson (1921) The anatomy and physics of the temporomandibular joint. Bull Nat DA 8(3): 236-241.

16. Erkan Arat, Deniz Sen, Bullent Sermet (1997) Investigation of intercondylar distance of Turkish population. Gu Dishek, Fak Derg 14: 95-99.

17. B Lazic, B Tepavcevic, J Keros (2006) Intercondylar distances of the human temporomandibular joints. Coll Antropol 30(1): 37-41.

18. A Keshvad, RB Winstanley, T Hooshmand (2000) Intercondylar width as a guide to setting up complete denture teeth. J Oral Rehabil 27(3): $217-26$.

19. S Mutinelli, M Manfredi, M Cozzani (2002) A mathematic- geometric model to calculate variation in mandibular arch form. Eur J Orthod 22(2): 113-125.

20. Trivino T, Siqueira DF, Scanavini MA (2008) A new concept of mandibular dental arch forms with normal occlusion. Am J Orthod Dentofacial Orthop 133(1): 10.e15-22.
Your next submission with Juniper Publishers will reach you the below assets

- Quality Editorial service

- Swift Peer Review

- Reprints availability

- E-prints Service

- Manuscript Podcast for convenient understanding

- Global attainment for your research

- Manuscript accessibility in different formats

( Pdf, E-pub, Full Text, Audio)

- Unceasing customer service

Track the below URL for one-step submission https://juniperpublishers.com/online-submission.php 